
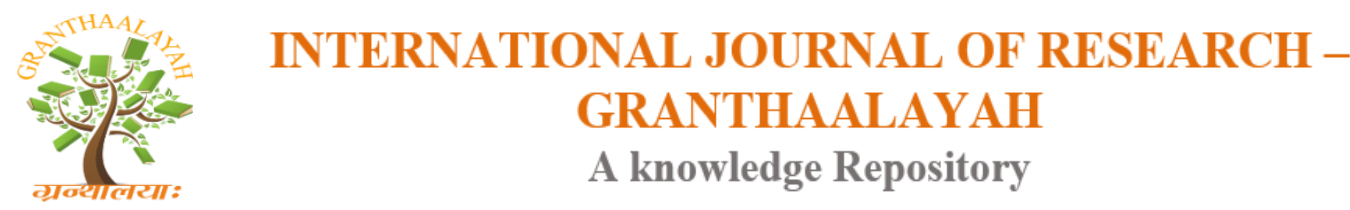

Science

\title{
PROPORTIONS IN ARCHITECTURE
}

\author{
Ar. Minakshi Rajput Singh *1 \\ *1 Associate Professor Amity School of Architecture and Planning, Amity University \\ Chhattisgarh, Raipur, India
}

\begin{abstract}
The uniqueness of His creation is reflected in different fields of life by the great masters throughout the ages that have born with the formation of the universe, from the big bang, till times still to come. Special ratio that can be used to describe the proportions of everything from nature's smallest building blocks, such as atoms, to the most advanced patterns in the universe, such as unimaginably large celestial bodies.

One of the key evidences presented for creation is the recurring appearance of the Divine proportion, or golden section, throughout the design of the human body and other life forms. An attempt has been made to relate Sri yantra and golden ratio and the various forms that seem to exemplify in the plan and elevation of the Indian temple. The yantra which is a complex geometry has been perfected to be used for the development of temple forms of different eras. The following paper will be a tool for the researchers to use the yantra in deriving the spaces of Indian temples.
\end{abstract}

Keywords: Proportions; Golden Section; Sri Yantra; Indian Temple Architecture.

Cite This Article: Ar. Minakshi Rajput Singh. (2018). "PROPORTIONS IN ARCHITECTURE." International Journal of Research - Granthaalayah, 6(3), 126-133. https:// doi.org/10.29121/granthaalayah.v6.i3.2018.1505.

\section{Introduction}

What makes us fill with awe in our historic architecture. The architecture of our glorious past since centuries and millennia has been rendered with spatial qualities which are to be studied and incorporated in the contemporary designs.

Roman architect vitruvius (1624) explained 3 conditions of a good building- commodity (usefulness), firmness (strength), and delight (beauty).

Proportions, play a vital role in framing the guidelines for creating useful spaces, designing structural systems and creation of aesthetically pleasing environs. Proportions of a space dramatically changes the perceptions of a person on that space and eventually the proportions of the external skin of the building can render it welcoming or threatening. 
Proportions are the relation that exists between the elements of an entire work and of the entire work to a certain part or element selected as a module. It is an accepted pattern of composition which pleases everyone. It is the rational integration of all the parts of a building in such a way that every part has its absolutely fixed size and shape, and it is bound to loose its harmony if anything is added to or subtracted from it. Mathematically, it can be expressed to be an equation proved to be true. For eg, proportions in all the creations of the god, or in other words, exemplifying golden ratio or divine proportions.

Identification of divine proportions has been studied several times in all the fields of life throughout the times defined.

There have been examples, in the field of architecture, of buildings which seem to exhibit golden section in their designs. One of the most proportionate building is the parthenon at acropolis, athens- exhibiting golden section. The derivation of the proportioning systems from the golden ratio is the objective of this paper.

Sri yantra and its relation with golden section and probability to be used as a tool for designing indian temple will be studied taking example of an ancient temple. The result of the study shall be recorded in the form of drawings.

\section{Study of Golden Ratio in Architecture}

The Parthenon, in Greek Architecture, exemplifies a certain symmetry, a certain harmony of part to part, and of part to the whole," explains Jeffrey M. Hurwit, an art historian at the University of Oregon. "There's no question that the harmony of the building, which is clearly one of its most visible characteristics, is dependent upon a certain mathematical system of proportions."

"Although the building looks straight, there's barely a straight line on it,". The convexity in every straight line is rendered perfectly. The Greek architects 2,500 years ago, knew about visual rays and optical illusion. The aim of the study is to explain translation of this knowledge of Greeks into building a magnificent edifice. The Parthenon being an important building of classical Greece exhibit the proportions approximating the golden ratio in every element of the facade, eg. the doric colonnade.

\section{Sriyantra Related to Divine Ratio}

The Sri yantra or Shri Chakra is a YANTRA formed by nine interlocking triangles that surround and radiate out from the central point, the junction point between the physical universe and its unmanifest source. 


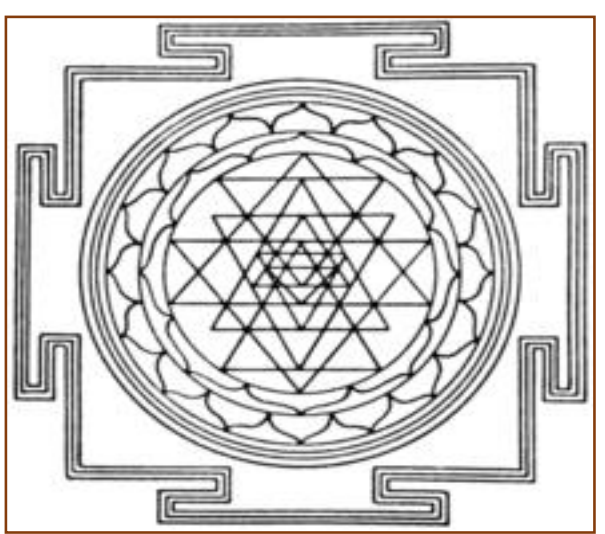

These 9 interlocking triangles are the isosceles triangles formed through the golden rectangle and constitute the family of golden triangles, 4 of them point upwards and represent the female energy Shakti, the other 5 point downwards, representing the male energy Shiva.

Triangles have 3 lengths, the base length, the slant length and the height. The angle at the intersection of these lengths plays a major role. The angle subtended at the base of the triangle in the yantra is around 51 degrees, the same value that is seen to be exhibited at the base of the Great Pyramid of Giza.

There seem to present different versions of Sri yantra, in the form of 9 interwoven triangles and constituting a total of 43 triangles, while some have circles and squares surrounding the triangles giving another square -circle sequence. The centre of the Yantra has a Bindu (dot),

The Sri yantra seem to exhibit a simple geometry but its construction has complexities. There are innumerous intersections that take place between the lines of the 9 triangles, and these cuts are supposed to be concurrent. Thus, a change in the position of any one shape will deliver adjustments in all the corresponding figures. If the intersection of the lines does not happen at a particular point, the concurrency is lost.

A rectangle has two degrees of freedom: width and height. But with a triangle there is width, height, and length of the slanted side that give three degrees of freedom. We will study seven variations of Golden Ratio triangles when a right angle triangle is used versus an isosceles one.

\section{The King And Queen of the Golden Triangles}

The King and Queen of the golden ratio triangles can be created from the golden rectangle by removing one of the sides and collapsing the two open sides until they meet in the middle. Interestingly the angles of these two triangles are all multiples of 36.

This triangle has two angles of 72 degrees and one angle of 36 degrees. The angles are all multiples of 36. If the base is of length 1 then the slanted sides will be of length 1.6180, which is symbolized by the Greek letter phi $(\varphi)$. 
If the 72 degrees angle is bisected we see that another smaller golden ratio triangle appears. This shows the self similar property of the golden ratio at work. The same self replication effect is noticed with the golden rectangle.

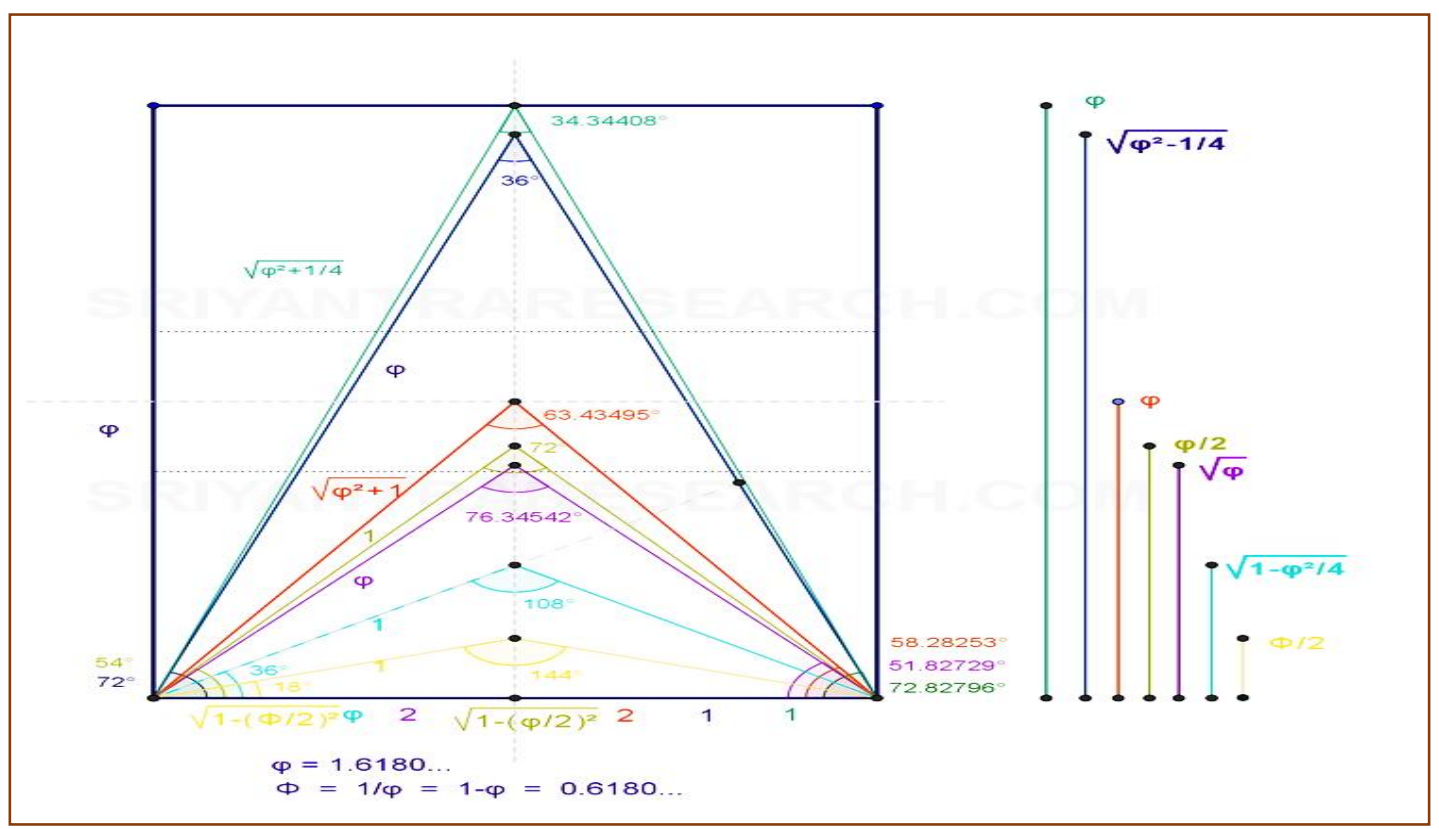

The golden triangles inside a golden rectangle

\section{The Family of the Golden Triangles}

This figure shows all the golden ratio triangles fitted inside a golden rectangle. We could divide the golden ratio in three families. First we have the triangles with even angles that are a multiple of 18. This can be further divided in two groups. The King and Queen of the golden ratio triangles are the first two that we generated by collapsing the sides of the golden rectangle. The sides of these two triangles have length 1 or $\varphi$. A third group would include the triangles that have irrational angles: $51.82 \ldots, 58.28 \ldots, 72.82 \ldots$

\section{Study of Ancient Indian Temple Architecture}

Indian temple architecture has been a subject that is widely studied and documented whereas analysis of the geometry of temples is still in its initial stages. Application of the Sri yantra to the temple plan and elevation for understanding the relationship between the philosophy underlying Hindu temple architecture and its practical applications is the aim of this paper.

The existing theories and concepts, like the mandala, Sri yantra and diagonal grid need to be reevaluated for their effective use in temple design. The published Sri yantra drawings need to be modified to be made fit for direct application on temple plans and elevations. The study establishes relationship between Sri yantra and temple plan and elevation. The ancient diagram yantra usually because of its complex nature has been limited to its role as a device for meditation. 
The orthogonal nature of the Vastu purushmandala, would render it difficult to construct on site, besides its inability to conceptually detail intricate temple designs and locate them on site. Besides problems relating to plan, it would be practically impossible to apply it for elevation design and construction.

This part of the study focuses on finding the correct way to locate the Sri yantra besides attempting to find out how extensively the Sri yantra can be applied to the north Indian temples. In order to conduct this analysis firstly the Sri yantra has to be drafted correctly and then it should be tested on various temples irrespsctive of their type.

There is a need to further explore a much larger possibility of Sri yantra's role as a design parameter for the Hindu temple architecture, which is primarily based on the traditional system.

\section{Sriyantra and Its Two Types}

Although the basic governing principle of both the types is the same, the final result is quite different. The first one is used for meditation purposes. The latter one if drafted correctly, is applicable for temple design and planning.

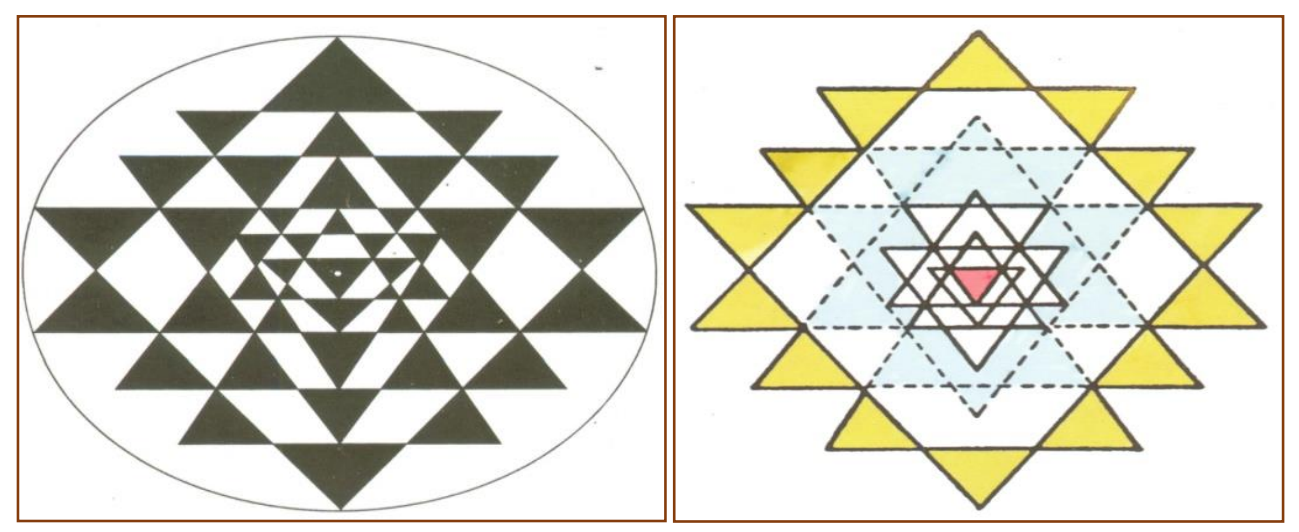

The possibility that the first type of Sri yantra has been used for temples is low because, a temple plan is based on symmetry. The plan's orthogonal characteristic is maintained at all times and therefore the diagonal grids can also be applied successfully. Hence, under these considerations the second type of the Sri yantra which maintains its parallel lines at all time was adopted for this study. Its method of construction has been shown step by step and its application has been studied for the temple plans.

The complete yantra is not placed on the garbhagriha until and unless we equate the 16 petals of the Sri yantra to the 16 pointed star.

On placing the Sri yantra on the plans and elevations correctly, some astonishing results can be recorded and it can be said for definite that the Sri yantra plays a crucial role in the placement and location of the various important points on the plan as well as the elevation.

The complete Sri yantra is formed and summarized in the figure below. 


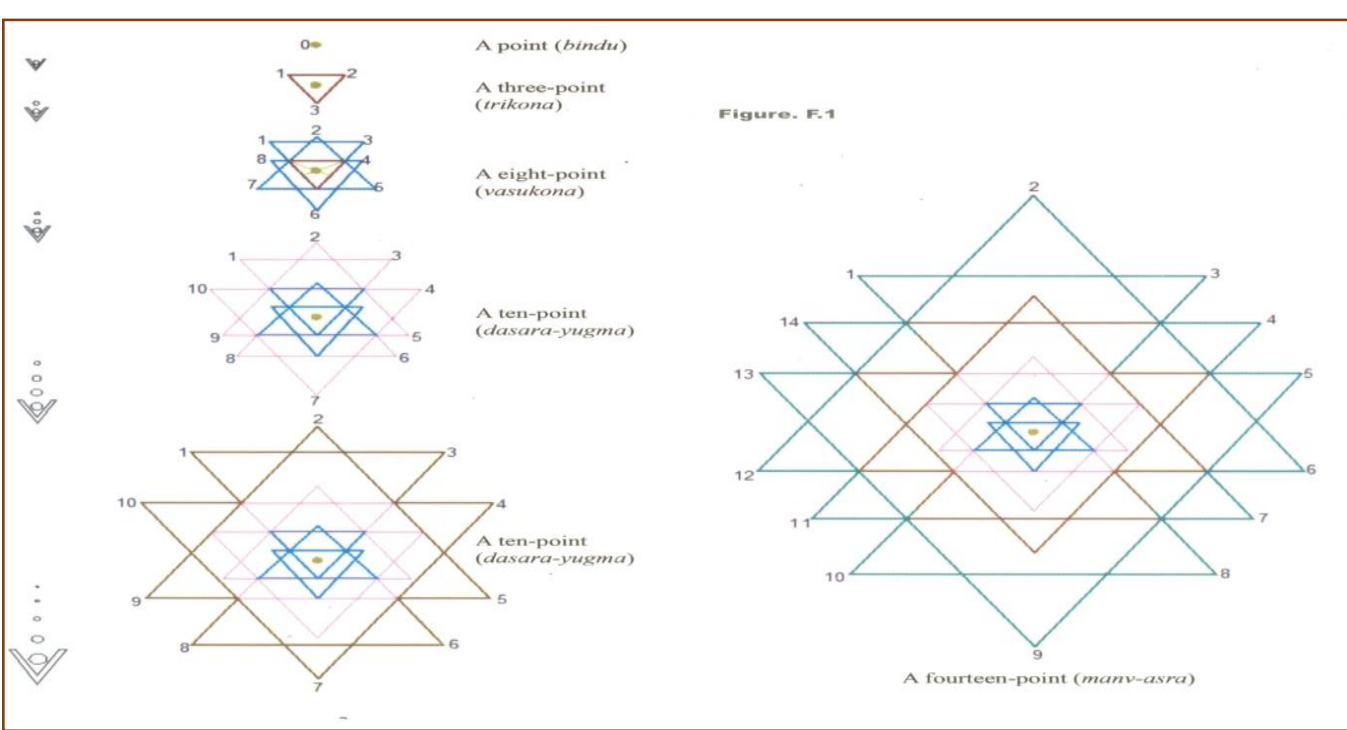

Sri Yantra as Drafted in Autocad

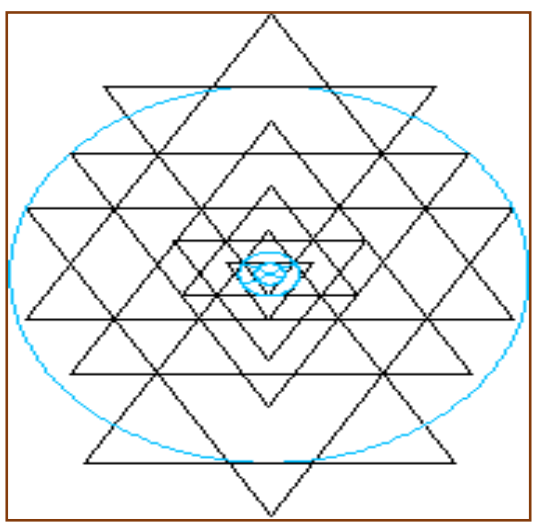

\section{Study of Lakshamana Temple at Khajuraho and the Possible Derivation from Sriyantra}

The Lakshamana temple, dedicated to the Vaikuntha form of Vishnu, having four subsidiary shrines located at the four corners. Lakshamana has the essential elements of a Khajuraho temple's plan- front hall (mukhamandapa), closed hall (gudhamandapa), vestibule in front of the sanctum door (antrala) and sanctum (garbhagriha). These elements are all aligned on a single axis. The east facing temple has the overall dimensions of $85^{\prime} \times 44^{\prime}$. The height of the temple is 80 '. Building material is sandstone that was brought from the neighbouring quarries, of varying shades of pink, buff or pale yellow.

It was built by Chandela Ruler Yashovarman (930-950 A.D). Unlike other temples in Khajuraho, its sanctum is Pancha-ratha on plan. Its shikhara is clustered with minor shikharas.

The wall portion is studded with balconied windows with ornate balustrades.

Objective of the Study is to trace the evolution of the major parts of the temple with respect to the Sri yantra as stated. 
The images of the plan and elevation of the temple with superimposed images of Sri yantra have been worked out using the software's: AutoCAD, MS Office Picture Manager.

It can be seen that the lines of the Sri Yantra governs or coincides with the key points, the position of the deity governing the entrance and vice- versa, in plan and the varying heights of all the features, in elevation of the temple. However, the study is been restricted to the detailed study thereby giving a platform for any further research. There can also be some ambiguity which may be rectified with the measured drawings of the temple.

THE FOLLOWING FIGURE SHOW THE PLAN OF LAKSHMANA TEMPLE WITH SUPERIMPOSED SRI YANTRA (NOT TO SCALE)

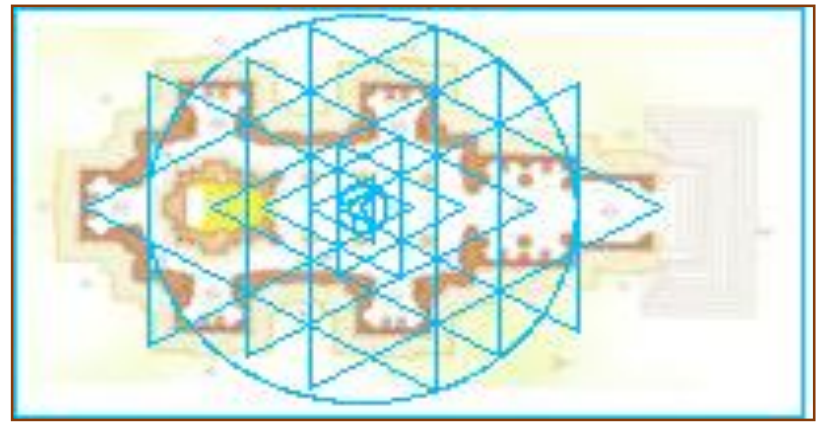

THE FOLLOWING FIGURE SHOW THE ELEVATION OF LAKSHMANA TEMPLE WITH SUPERIMPOSED SRI YANTRA (NOT TO SCALE)

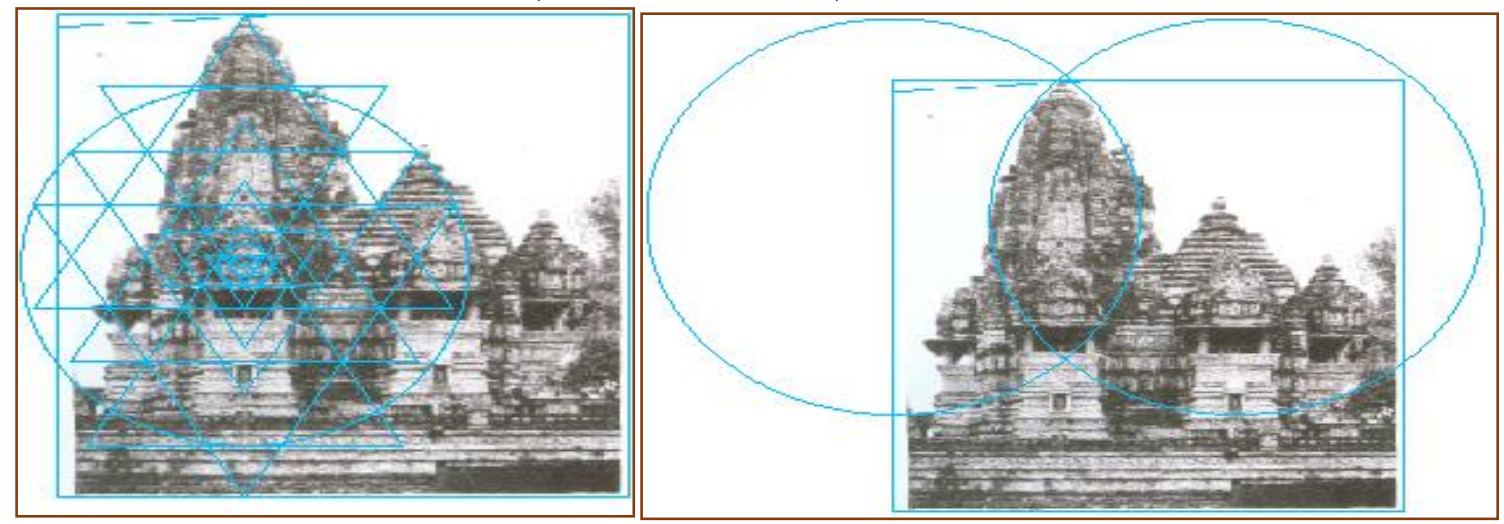

\section{Conclusion}

An attempt to prove the relation between Golden Ratio and Sri yantra and using Sri yantra as a device to evolve the plan and elevation has been studied and found to be true in the temple taken for study purpose.

The construction of Hindu temples has always been a subject of study through various ancient yantras, mandalas, that needs to be rediscovered and documented. A new perspective into the relation between the Sri yantra, its significance and role in design of Indian temple would create a wide scope of research by taking examples of temples of different era. 


\section{References}

[1] Dr. Gandotra Ananya. Indian Temple Architecture Analysis of Plans, Elevations and Sections VOL 1-2-3. Shubhi Publications, 2011

[2] Vitruvius.The Ten Books on Architecture. Bibliolife DBA of Bibilio Bazaar II LLC, 2015

[3] Dr. Pandya Yatin, Concepts of Space in Traditional Indian Architecture, Mapin, 2005

[4] Stierlin Henri, Hindu India: From Khajuraho to the Temple City of Madurai, Taschen, 1998

[5] Tadgell Christopher, The History of Architecture in India, Phaidon Press 1994.

*Corresponding author.

E-mail address: ar.minakshisingh@ gmail.com 